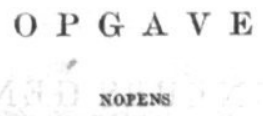

DE HOOGE REGERING VAN NEDERLANDSCH INUIE,

VAN 1816 TOT 1860 .

In hoeverre de behoefte zich heeft doen gevoelen aan naamlijsten van hoofden van Indisch bestuur met aanwijzing van den tijd der vervulling hunner betrekking, is vroeger in deze Bijdragen reeds aangetoond. Daar die noodzakelijkheid niet zoo regtstreeks spreekt van dat gedeelte der Indische regering, waarvan hierbij de opgave geschiedt, zoo kan het evenwel voor velen van bijzonder en zelfs zakelijk belang zijn, ook daaromtrent de noodige aanwijzingen te kunnen vinden.

Meenende dat de opgave betrekkelijk de Raden van Indië daartoe eene eerste plaats bekleedt, acht men het niet ondienstig en tevens geschikt, de opgaven betreffende de GouverneursGeneraal, Kommissarissen-Generaal en Vice-Presidenten van den Raad van Nederlandsch Indië, te doen voorafgaan; wel is waar komen de namen der Gouverneurs- en Kommissarissen-Generaal in andere tijdwerken steeds voor, maar zonder de hier gevolgde bijvoeging van data. Achter de gemelde lijst der Raden van Indië volgt die der Algemeene Secretarissen als tevens behoorende onder de rubriek aan het hoofd dezer gemeld.

Nadere aanwijzingen zijn slechts dáár gegeven, waar zulks nuttig of wenschelijk kon worden geacht; terwijl bij de vroegere opgaven van de Hoofden van Gewestelijk Bestuur op Java en Madura, toelichtingen gegeven zijn betrekkelijk de aangegeven nommers der Couranten (zie Bijdragen, Nieuwe Volgreeks, 3e Deel, bl. 118), die bij de tegenwoordige opgave mede van toepassing zijn,

's Gravenhage, 31 Jan. 1861.

M. A, VAN DER KLOOT. 


\section{GOUVERNEURS GENERAAL}

vax

NEDERLANDSCH INDIE,

vaN 1816 TOT 1860.

\begin{tabular}{|c|c|c|}
\hline \multicolumn{2}{|c|}{$\begin{array}{l}\text { DAGTEEKENING } \\
\text { DER AANVAARDING } \\
\text { VAN HET BESTUUR. }\end{array}$} & N A M E N. \\
\hline 19 Augustus & 1816. & G. A. G. P. Baron van der Capellen (Kommissaris Generaal). \\
\hline 16 Januarij & 1819. & Idem $^{1}$ \\
\hline 1 Januarij & 1826. & H. M. de Kock (Luitenant-Gouverneur-Generaal). \\
\hline 16 Januarij & 1830. & J. van den Bosch. \\
\hline 2 Julij & 1833. & J. C. Baud (ad interum) ${ }^{2}$. \\
\hline 29 Februarij & 1836. & D. J. de Eerens. Overleden 30 Mei $1840^{3}$. \\
\hline 1 Junij & 1840. & C. S. W. Graaf van Hogendorp (waarnemend). \\
\hline 6 Januarij & 1841. & Mr. P. Merkus (waarnemend). \\
\hline 14 Februarij & 1843. & Idem. Overleden 2 Augustus 1844. \\
\hline 5 Augustus & 1844. & Jonkhr. J. C. Reijnst (waarnemend). \\
\hline 28 September & 1845 . & $\begin{array}{l}\text { J. J. Rochussen. } \\
\text { Mr. G. J. Bruce. Overleden vóór zijn vertrek naar Indië } \\
\text { den } 30^{\text {sten }} \text { December } 1850 \text {. }\end{array}$ \\
\hline $12 \mathrm{Mei}$ & 1851. & Mr. A. J. Düjmaer van Twist. \\
\hline $22 \mathrm{Mei}$ & 1856. & C. F. Pahud. \\
\hline
\end{tabular}

1 De Heer van der Capellen, Kommissaris Generaal en Gouverneur Generaal, aanvaardt eerst op den 16 Januarij 1819, bij de plegtige inwijding der Indische Regering, zijne betrekking van Gouverneur Generaal.

2 De Heer Band, Directeur voor de zaken der koloniën, heeft van den $23 \mathrm{Ja}$ nuarij 1833 tot den 2 Julij 1833 de betrekking bekloed van Vice-President der Indische Regering.

3 De Heer de Eerens, Luitenant-Generaal, heeft den 5 Maart 1835 zitting genomen als Luitenant-Gouverneur-Generaal. 


\section{KOMMISSARISSEN GENERAAL}

\section{NEDERLANDSCH INDIE,} SEDERT 1816.

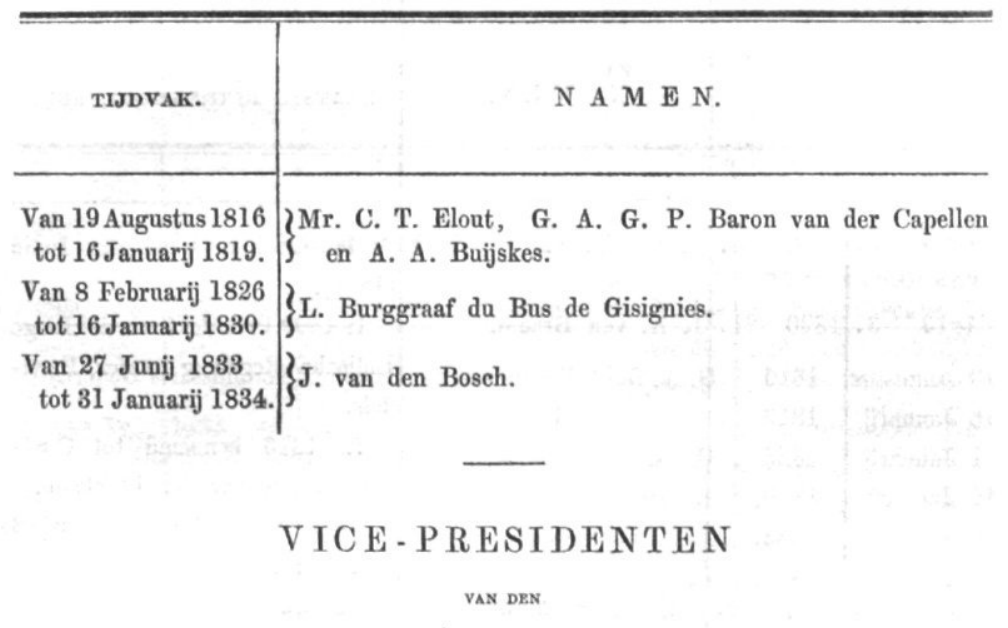

\section{RAAD VAN NÉDERLANDSCH INDIE,} SEDERT 1836.

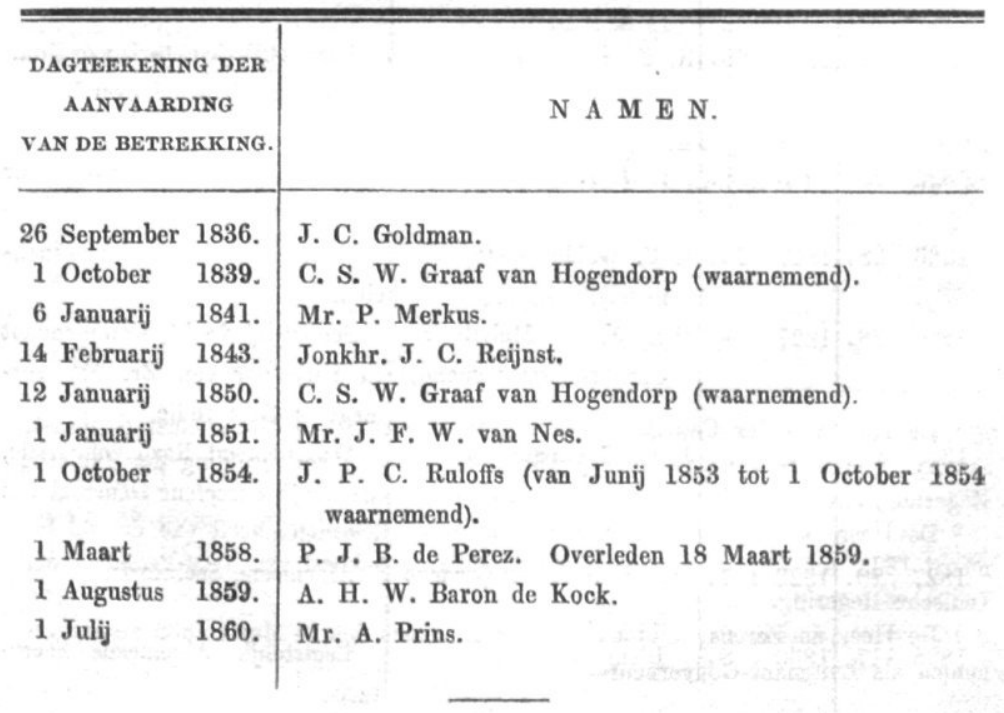




\section{E D E N}

vAN DEN

\section{RAAD VAN NEDERLANDSCH INDIE,}

VAN 1819 TOT 1860.

\begin{tabular}{|c|c|c|c|}
\hline $\begin{array}{r}\text { JAAR EN } \\
\text { DER BATAVIA } \\
\text { JAVASCHE } \\
\text { HOUDENDE } \\
\text { DE } \\
\text { DENOEMTNG. }\end{array}$ & $\begin{array}{l}\text { NOMDOER } \\
\text { ASCHE, LATER } \\
\text { COURANT, } \\
\text { VERBMEDING } \\
\text { N : } \\
\begin{array}{l}\text { HET AFrRE- } \\
\text { DEN OY OVRI } \\
\text { LIDEN, ENZ. }\end{array}\end{array}$ & N A M E N. & LAATSTE BETREKKISG, ENZ. \\
\hline 1819 & 1830 & P. T. Chassé. & $\begin{array}{l}\text { Oud-Ordinair-Raad van Indië } \\
(1808) \text {. }\end{array}$ \\
\hline 1819 & 1820 & J. A. van Braam. & $\begin{array}{l}\text { In } 1809 \text { President van de Hooge } \\
\text { Indische Regering onder Daen- } \\
\text { dels. } \\
\text { In } 1816 \text { benoemd tot Oost- } \\
\text { Ind. Ambtenaar der 1e klasse. } \\
\text { Overleden te Batavia, den } 12 \\
\text { Mei } 1820 \text {. }\end{array}$ \\
\hline 1819 & 1827 & Mr. H. W. Muntinghe. & $\begin{array}{l}\text { In } 1809 \text { Extra-Ordinair-Raad } \\
\text { van Indië, en gefungeerd als } 20 \\
\text { lid van dien Raad onder het } \\
\text { Britsch Tusschen-Bestuur tot No- } \\
\text { vember } 1813 \text {. }\end{array}$ \\
\hline 1819 & 1826 & R. d'Ozy. & $\begin{array}{l}\text { Laatstelijk Secretaris van Kom- } \\
\text { missarissen Generaal over Neder- } \\
\text { landsch Indië. }\end{array}$ \\
\hline 1820 & 1826 & Mr. H. J. van de Graaff. & $\begin{array}{l}\text { Laatstelijk Hoofd-Inspecteur } \\
\text { van de Financiën. }\end{array}$ \\
\hline 1826 & 1827 & $\begin{array}{l}\text { J. C. Goldman (waarne. } \\
\text { mend). }\end{array}$ & $\begin{array}{l}\text { Hoofd-Directeur van Finan- } \\
\text { ciën. }\end{array}$ \\
\hline 1826 & 1827 & $\begin{array}{c}\text { Jhr. J. J. Melvill van } \\
\text { Carnbee (waarnemend). }\end{array}$ & $\begin{array}{l}\text { Schout-bij-Nacht, Kommandant } \\
\text { en Directeur van Zr. Ms. zee- } \\
\text { magt in Oost-Indië. }\end{array}$ \\
\hline 1827 & 1830 & J. C. Goldman. & $\begin{array}{l}\text { Waarnemend Raad van Indië, } \\
\text { laatstelijk Directeur Generaal van } \\
\text { Financiën. }\end{array}$ \\
\hline 1827 & 1828117. & $\begin{array}{l}\text { Mr. J. Bousquet (waarne- } \\
\text { mend). }\end{array}$ & Algemeene Secretaris. \\
\hline 1828117. & 1830 & Idem idem. & $\begin{array}{l}\text { Laatstelijk Algemeene Secre- } \\
\text { taris. }\end{array}$ \\
\hline
\end{tabular}




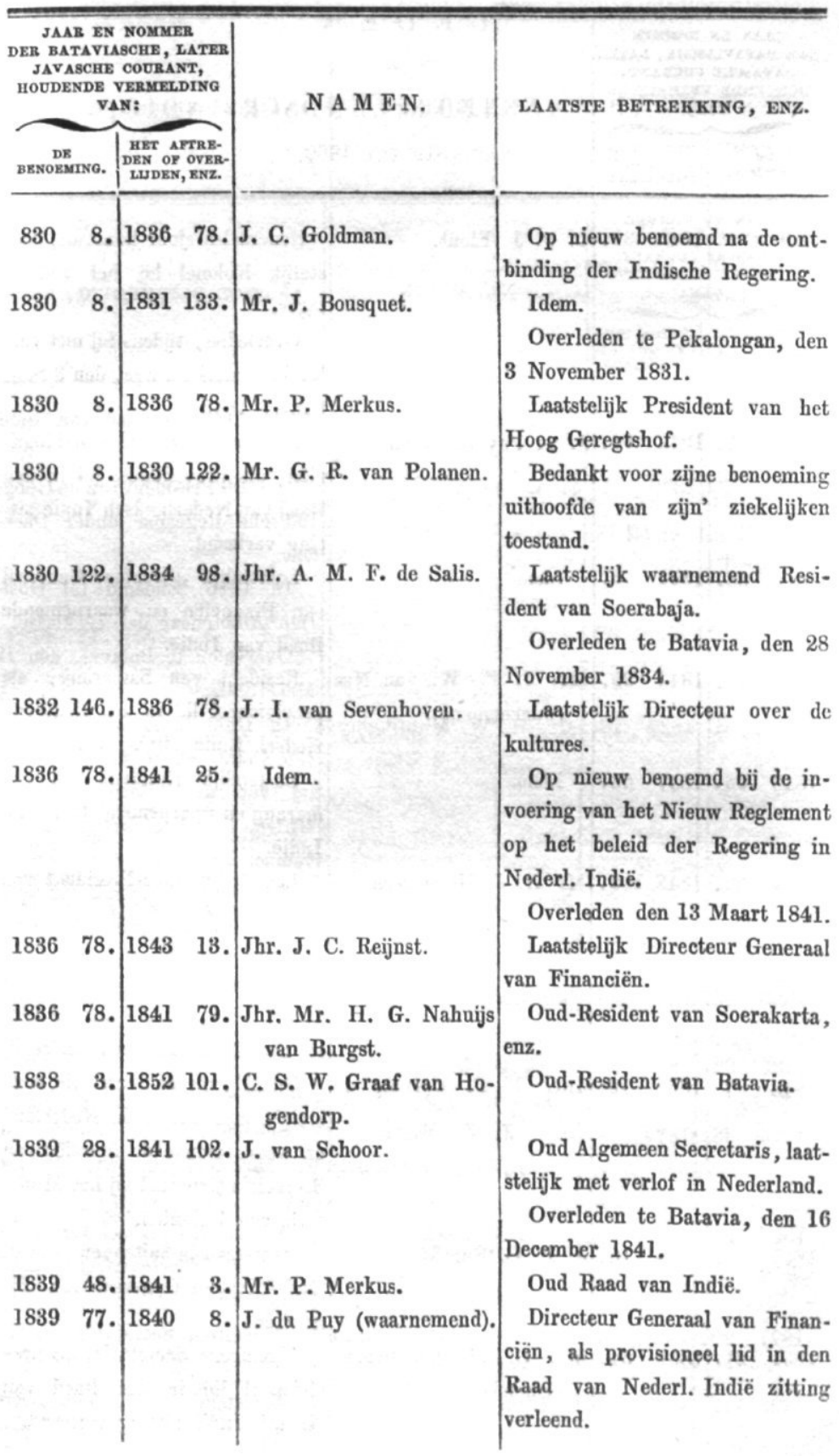


$t$

\begin{tabular}{|c|c|c|c|}
\hline 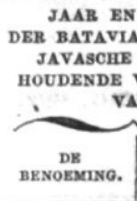 & $\begin{array}{l}\text { NOMOMER } \\
\text { ISCHE, LATER } \\
\text { COURANT, } \\
\text { VEBMELDING } \\
\text { IN : } \\
\begin{array}{l}\text { HET AFTRE- } \\
\text { DEN OF OVER- } \\
\text { LIJDEN, ENZ. }\end{array}\end{array}$ & NA MEN. & LAATSTE BETREKKNNG, ENZ. \\
\hline $1840 \quad 5$. & 184399. & C. P. J. Elout. & $\begin{array}{l}\text { Generaal-Majoor honorair, laat- } \\
\text { stelijk Kolonel bij het Indisch } \\
\text { leger. } \\
\text { Overleden, tijdens hij met ver- } \\
\text { lof in Nederland was, den } 3 \text { Sep- } \\
\text { tember } 1843 \text {. }\end{array}$ \\
\hline 184288. & 185156. & $\begin{array}{l}\text { J. du Puy (waarnemend). } \\
\text { Idem. }\end{array}$ & $\begin{array}{l}\text { Directeur Generaal van Finan- } \\
\text { ciën, als provisioneel lid in den } \\
\text { Raad van Nederlandsch Indië zit- } \\
\text { ting verleend. } \\
\text { Laatstelijk Directeur Generaal } \\
\text { van Financiën en waarnemende } \\
\text { Raad van Indië. }\end{array}$ \\
\hline 184317. & 184753. & $\begin{array}{l}\text { Mr. J. F. W. van Nes } \\
\text { (waarnemend). } \\
\text { Idem. }\end{array}$ & $\begin{array}{l}\text { Resident van Samarang, als } \\
\text { provisioneel lid in den Raad van } \\
\text { Nederl. Indië zitting verleend. } \\
\text { Laatstelijk Resident van Sa- } \\
\text { marang en waarnemend Raad van } \\
\text { Indië. }\end{array}$ \\
\hline 184483. & 1848102. & Mr H. J. Hoogeveen. & $\begin{array}{l}\text { Laatstelijk Vice-President van } \\
\text { het Hoog Geregtshof van Ne- } \\
\text { derlandsch Indië. } \\
\text { Overleden te Batavia, den } 13 \\
\text { Maart } 1849 \text {, nadat hem een ver- } \\
\text { lof naar Nederland was verleend. }\end{array}$ \\
\hline $1848 \quad 7$. & 1851 & $\begin{array}{l}\text { Jhr. J. P. Cornets de } \\
\text { Groot. }\end{array}$ & $\begin{array}{l}\text { OndAlgemeene Secretaris, laat- } \\
\text { stelijk met verlof in Nederland } \\
\text { en waarntmende de functiën van } \\
\text { Secretaris Generaal bij het Minis- } \\
\text { terie van Koloniën. }\end{array}$ \\
\hline 1849104. & $1854 \quad 18$ & J. P. C. Ruloffs. & $\begin{array}{l}\text { Staatsraad in buitengew. dienst, } \\
\text { Oud-Directeur Generaal van Fi- } \\
\text { nanciēn. }\end{array}$ \\
\hline 1851 & 1851 & $\begin{array}{l}\text { Mr. C. Visscher (waar- } \\
\text { nemend). }\end{array}$ & $\begin{array}{l}\text { Algemeene Secretaris, als pro- } \\
\text { visioneel lid in den Raad van } \\
\text { Nederl. Indië zitting verleend. }\end{array}$ \\
\hline
\end{tabular}




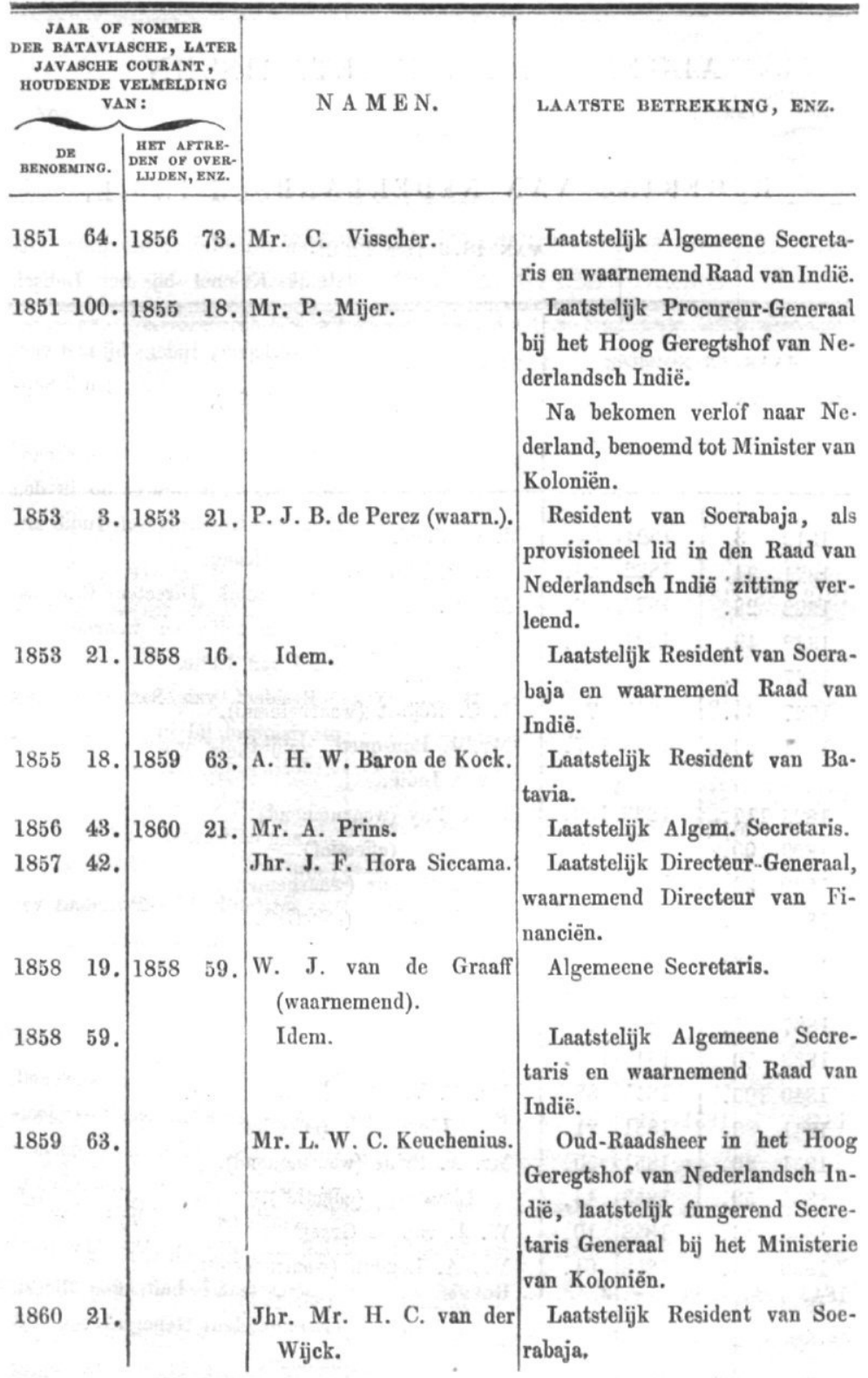




\section{ALGEMEENE SECRETARISSEN}

DER

\section{REGERING VAN NEDERLANDSCH.INDIE,}

VAN 1819 TOT 1860.

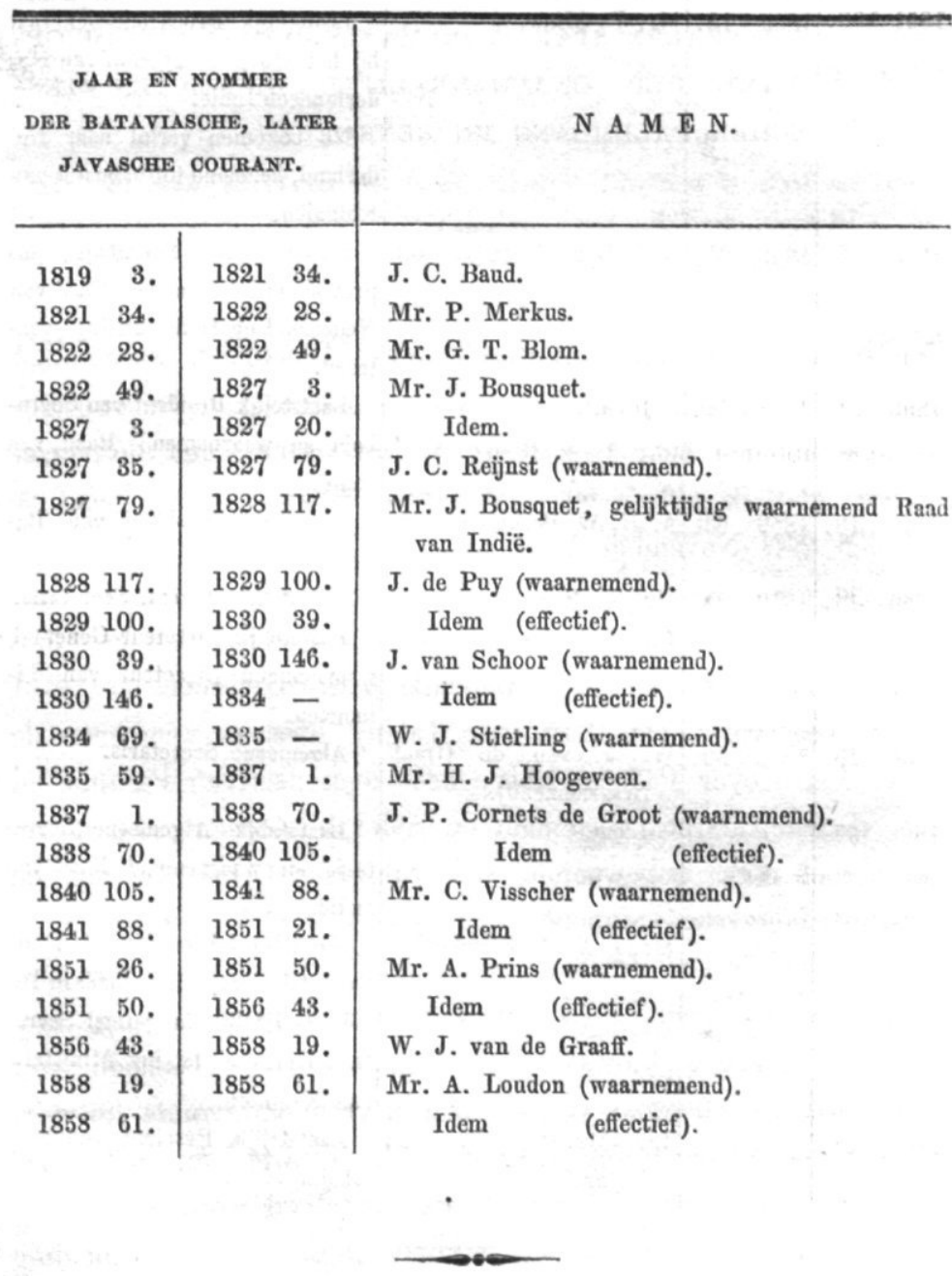

